\title{
СОДЕРЖАНИЕ ПОДВИЖНЫХ ФОРМ МИКРОЭЛЕМЕНТОВ В АЛЛЮВИАЛЬНЫХ ПОЧВАХ ПОЙМЫ СРЕДНЕГО ТЕЧЕНИЯ Р. АМУР И ВЛИЯНИЕ НА НИХ ПАВОДКА 2013 ГОДА
}

\author{
А. В. Мартынов \\ Институт геологии и природопользования ДВО РАН, Россия \\ Поступила в редакиию 11 апреля 2018 г.
}

\begin{abstract}
Аннотация: Приведены данные о содержании подвижных форм микроэлементов в аллювиальных почвах поймы среднего течения реки Амур. Определены последствия длительного затопления паводковыми водами в результате крупного наводнения в 2013 году на содержание подвижных микроэлементов. Установлено, что в аллювиальных почвах поймы активно накапливаются подвижные формы $\mathrm{Sr}, \mathrm{Ba} \mathrm{Cd}, \mathrm{Y}, \mathrm{U}$ и наблюдается дефицит таких элементов как - Sc, V, Cr, Cu, $\mathrm{Ga}, \mathrm{Zr}, \mathrm{Mo}, \mathrm{Cs}, \mathrm{Hf}$, W. Распределение по профилю подвижных микроэлементов обусловлено их аккумуляцией глинистыми минералами и органическим веществом. После паводка содержание микроэлементов, аккумулирующихся на глинистых минералах, преимущественно увеличилось, а связанных с органическим веществом снизилось.
\end{abstract}

Ключевые слова: подвижные микроэлементы, наводнение, река Амур, аллювиальные почвы, кластерный и корреляционный анализы.

The content of mobile forms of trace elements in the alluvial soils of the floodplain of the middle course. Cupid and the impact of the 2013 flood

\section{A. V. Martynov}

Abstract: Labile trace elements sufficiency was estimated in alluvial soils on the flood plain of middle reach of the Amur River. Effect of long flood water standing in 2013 on concentration of labile trace elements concentration was considered in the article. Accumulation of labile $\mathrm{Sr}, \mathrm{Ba} \mathrm{Cd}, \mathrm{Y}, \mathrm{U}$ and losses of $\mathrm{Sc}, \mathrm{V}, \mathrm{Cr}, \mathrm{Cu}, \mathrm{Ga}, \mathrm{Zr}, \mathrm{Mo}, \mathrm{Cs}, \mathrm{Hf}, \mathrm{W}$ has determined in studied alluvial soils. Vertical distribution of labile form of trace elements is mainly determined by their accumulation on clay minerals surface and organic matter. Concentration of elements which are accumulated on clay minerals increased after flood, other elements whose contents are controlled by organic matter have decreased.

Key words: mobile trace elements, flood, Amur River, alluvial soils, cluster and correlation analyzes.

В аллювиальных почвах изучение содержания и динамики микроэлементов (МЭ) связано с целым рядом трудностей, обусловленных высокой динамичностью пойменного ландшафта. Почвенный покров пойм характеризуется сильной пестротой и большим разнообразием свойств. Немаловажную роль в накоплении и миграции МЭ в аллювиальных почвах выполняет вода. Грунтовые и склоновые воды обуславливают как привнос МЭ в почвы, так и их вынос в ниже лежащие горизонты или за пределы почвенного профиля, что создает значительную сложность и пестроту распределения МЭ в почвах пойм. Но, наибольшее влияние на баланс МЭ в почвенном покрове пойм ока-

(C) Мартынов А.В., 2019 зывают паводки. Принято считать, что паводки обогащают почвы питательными элементами, содержащимися в аллохтонном растворенном и взвешенном веществе паводковых вод $[13,26]$. Вместе с тем, паводковые воды способны размывать уже сформированные почвы. В результате длительного затопления они изменяют геохимическую обстановку, обуславливая потери МЭ более высокие, чем их вносится с аллохтонным веществом [18].

Характер паводков, их интенсивность и частота, а также состав транспортируемого вещества обусловлен природными условиями региона (геологическим строением, климатическими условиями, характером растительного покрова, типом речной сети) и антропогенным влиянием [15]. 


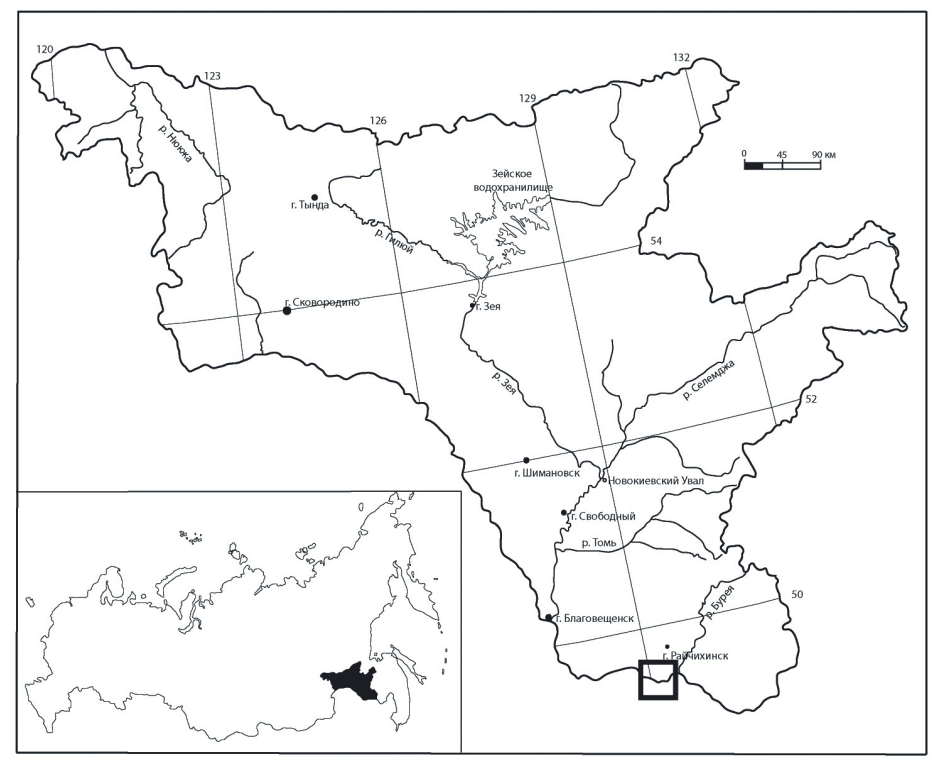

Puc. 1. Расположение ключевого участка на карте-схеме Амурской области

Следовательно, последствия влияния паводков на содержание микроэлементов в аллювиальных почвах в каждом случае индивидуальны и неповторимы. Поэтому цель данного исследования определить обеспеченность аллювиальных почв поймы реки Амур подвижными формами микроэлементов и выявить последствия катастрофического паводка 2013 года на их содержание. Подвижные формы редкоземельных элементов были рассмотрены ранее в работе Мартынова А. В. [7]. Учитывая вовлеченность значительной территории поймы Амура в сельскохозяйственную деятельность, подобная работа имеет важное практическое значение, так как позволяет оценить вклад паводков в обеспеченность аллювиальных почв жизненно важными для сельскохозяйственных культур микроэлементами.

\section{ОБЪЕКТ И МЕТОДЫ ИССЛЕДОВАНИЯ}

В качестве объекта исследования для оценки влияния паводка на содержание подвижных микроэлементов (ПМЭ) в аллювиальных почвах поймы среднего течения реки Амур выбран ключевой участок, расположенный перед устьем реки Бурея (рис. 1). Данный выбор обусловлен проведением в данном районе детальных почвенных исследований с отбором почвенных проб за два года до паводка, что дает возможность сравнить геохимическое состояние аллювиальных почв до него и после.

Пойменный массив в пределах ключевого участка достигает 10 км ширины и 12 метров высоты относительно условного уреза реки. В ходе экс- педиции, после паводка, установлено, что подъем воды на данном участке составил около 6 метров. Это привело к полному затоплению семи заложенных в 2011 году почвенных разрезов в пределах прирусловой поймы. Отобрать образцы удалось только из трех разрезов. Образцы отбирались по генетическим горизонтам: восемь образцов до паводка и девять после паводка. Идентификация почв была сделана в соответствии с классификацией и диагностикой почв России [14].

В отобранных почвенных образцах были определены: гранулометрический состав - методом пипетки по Н. А. Качинскому; потенциальная кислотность - потенциометрически; обменная кислотность и подвижный алюминий методом А. В. Соколова; обменный кальций и магний - комплексонометрическим методом по К. К. Гедройцу; органический углерод - методом мокрого озоления по И.В. Тюрину в модификации Б. А. Никитина [1, 9]. Валовой макроэлементный состав определен рентгенфлуоресцентным методом. Изучение свойств почв проводилось в аналитическом центре минералого-геохимических исследований ИГиП ДВО РАН.

Определение ПМЭ было выполнено методом масс-спектроскопии с индуктивно-связанной плазмой в аналитическом центре коллективного пользования на базе ДВГИ ДВО РАН под руководством н.с. Зарубиной Н. В. Для извлечения ПМЭ был использован ацетатно-аммонийный буфер с pH 4,8. Навеску воздушно-сухой пробы весом 5 г заливали буферным раствором и оставляли на сутки при комнатной температуре. За время контакта пробы с раствором производили кратковременное 


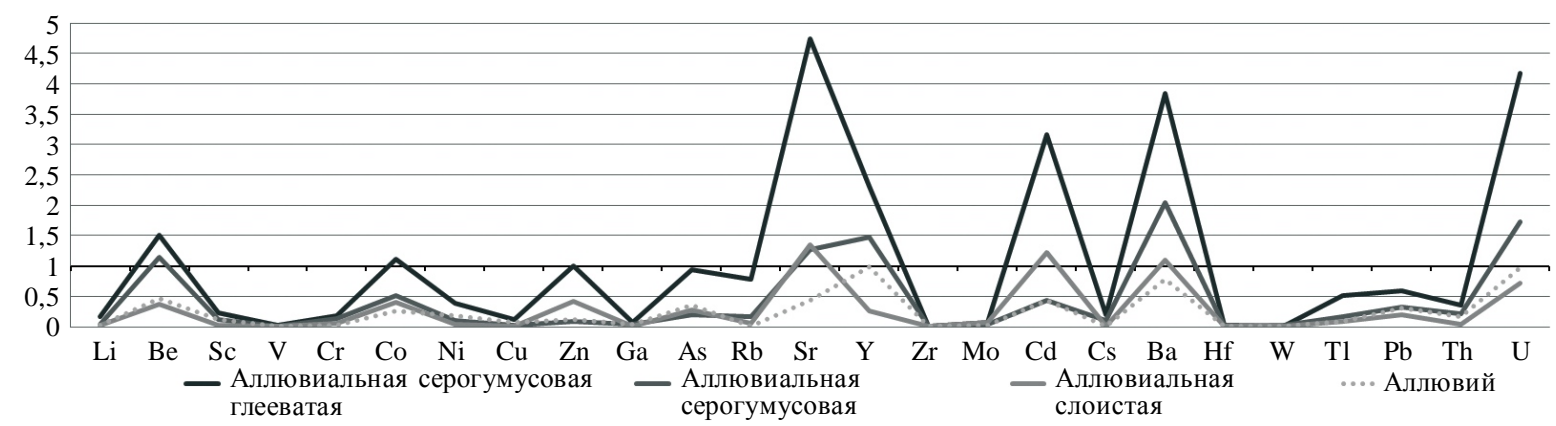

Puc. 2. Отношение среднего содержания подвижных форм микроэлементов в аллювиальных почвах к их среднему содержанию в почвах мира по Кабата-Пендиас [14]

перемешивание (7 раз). Полученные растворы минерализовали в микроволновой печи MARS-5 (CEM Corporation, USA). Анализ на широкий спектр элементов был выполнен на квадрупольном масс-спектрометре с индуктивно связанной плазмой (ИСП-МС) Agilent 7700x (Agilent Technologies, Япония).

Для выявления закономерностей между ПМЭ, макроэлементным составом и свойствами аллювиальных почв использовался корреляционный анализ (метод Пирсона). Полученные коэффициенты корреляции сгруппированы в кластеры методом К-средних. Количество кластеров определялось предварительно иерархическим методом (Метод Варда, Манхэттенское расстояние). Выбрано расстояние в 4 шага при длине 2,5. Так как часть данных характеризовалась ненормальным распределением, эти данные были стандартизированы. Статистическая обработка данных проводилась в программе Statistica v.6.0

Для оценки изменения содержания ПМЭ до и после паводка была использована формула

$$
N=100-((100 * N d) / N p),
$$

где $N$ - отношение содержания элементов после паводка к допаводковому значению в процентах, $N d$ - содержание элемента до паводка, $N p$ - содержание элемента после паводка. Полученные отношения были сгруппированы кластерным методом.

\section{РЕЗУЛЬТАТЫ И ОБСУЖДЕНИЕ}

По классификации почв России, исследуемые аллювиальные почвы относятся к двум отделам. Аллювиальная серогумусовая (АСГ) и аллювиальная серогумусовая глееватая почва (АСГГ) входят в отдел аллювиальных почв, а аллювиальная слоистая (AC) в отдел слаборазвитых почв. Паводок 2013 года вызвал значительные изменения в физико-химических и химических свойствах этих почв и их макроэлементном составе [5], которые не могли не сказаться на содержании микроэлементов.
Оценка содержания ПМЭ в исследуемых аллювиальных почвах до паводка затруднена отсутствием критериев. Для характеристики содержания валовых форм МЭ применяются их кларки, показатели фонового содержания, или же усредненное содержание МЭ в почвах мира или отдельной страны. Для изучения ПМЭ чаще всего используются агрохимические критерии оценки обеспеченности почв в целях выращивания сельскохозяйственных культур или же применяются ПДК, но они разработаны для небольшого числа ПМЭ $[2,16]$.

Чтобы выполнить оценку обеспеченности аллювиальных почв ПМЭ, были использованы данные по среднему валовому содержанию микроэлементов в почвах мира по Кабата-Пендиас [19]. От этих данных были взяты $5 \%$, представляющих минимальное количество ПМЭ. Также, на графике отображены данные, характеризующие содержание ПМЭ в аллювии, принесенном паводком и перекрывшим аллювиальную серогумусовую почву (горизонт W). Использование данных о содержании ПМЭ в аллювии, который фактически является почвообразующей породой для аллювиальных почв, позволяет оценить влияние процессов почвообразования на их содержание. Полученные результаты показывают, что исходный аллювий обеднен ПМЭ (рис. 2). Не выявлены $\mathrm{Nb}, \mathrm{Sn}$ и Ta, и отсутствуют элементы способные сформировать ассоциацию накопления. Только содержание $\mathrm{U}$ и Y сопоставимо со среднемировым, но не превышает его. В аллювиальных почвах при удалении от русла содержание подвижных форм ряда элементов $(\mathrm{Sr}, \mathrm{BaCd}, \mathrm{Y}, \mathrm{U})$ значительно увеличивается. Ассоциация рассеивания среди ПМЭ более обширна. Содержание $\mathrm{Sc}, \mathrm{V}, \mathrm{Cr}, \mathrm{Cu}, \mathrm{Ga}, \mathrm{Zr}, \mathrm{Mo}$, $\mathrm{Cs}, \mathrm{Hf}, \mathrm{W}$ в пойменномаллювии и разных типах почв близко к идентичному.

Содержание ПМЭ в почвах увеличивается от $\mathrm{AC}$ почвы до АСГг почвы, т.е. при удалении от 


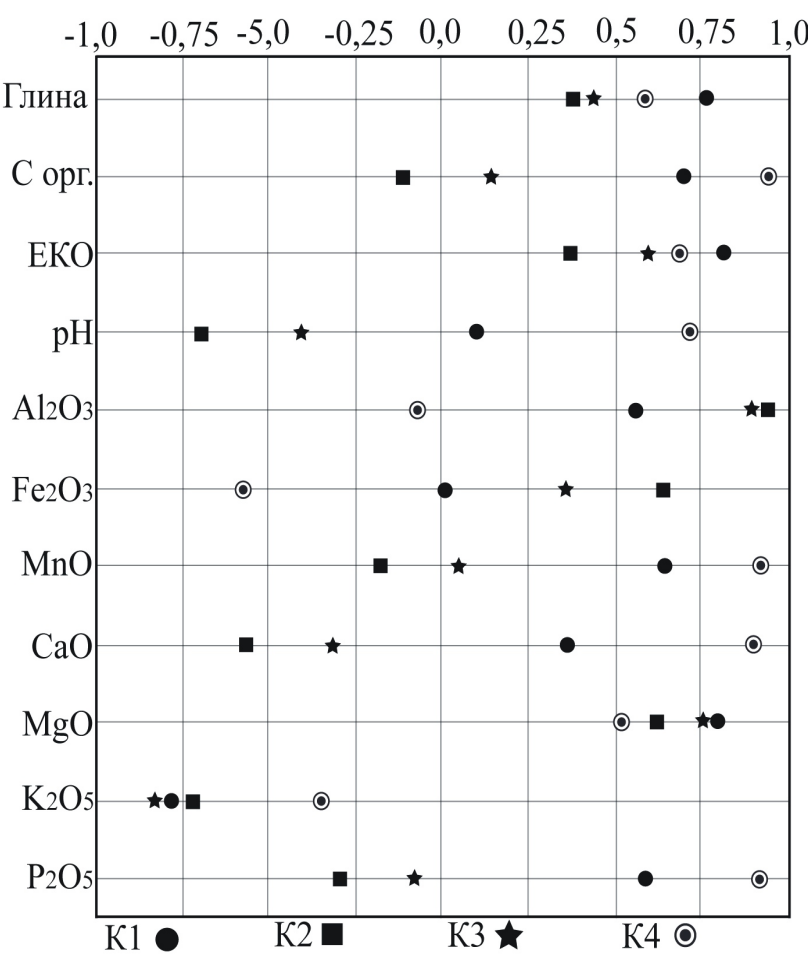

Рuc. 3. График средних по кластерам из коэффициентов корреляции содержания подвижных форм микроэлементов, валовых форм макроэлементов и свойств аллювиальных почв до паводка:

$\mathbf{K 1}: \mathrm{Rb}, \mathrm{Ba}, \mathrm{W}, \mathrm{Tl}, \mathrm{Pb}$;

K2:Be, Sc, Cr, Ga, Y, Hf, Th, U;

К3: $\mathrm{Co}, \mathrm{Ni}, \mathrm{Cu}, \mathrm{Zr}, \mathrm{Cs}$;

K4: $\mathrm{Li}, \mathrm{V}, \mathrm{Zn}, \mathrm{As}, \mathrm{Sr}, \mathrm{Mo}, \mathrm{Cd}$

русла (рис. 3). Это можно было бы объяснить утяжелением гранулометрического состава почв и увеличением содержания органического вещества. Но, для подтверждения предположения был выполнен корреляционный анализ между содержанием ПМЭ, свойствами почв и макроэлементным составом (рис. 3).

До паводка у элементов, входящих в кластеры 2 и 3, достоверные положительные коэффициенты корреляции $(\mathrm{R})$ с оксидами алюминия и магния (рис. 3). Алюминий, также как и магний, в молодых аллювиальных почвах преимущественно содержится в виде первичных алюмосиликатов и вторичных глинистых минералов [12], обладающих высоким сорбционным потенциалом [25]. Следовательно, элементы 2 и 3 кластеров аккумулируются преимущественно глинистыми минералами. Нужно отметить, что для элементов этих кластеров также характерны сильные отрицательные R c реакцией среды и оксидами кальция, т.е.

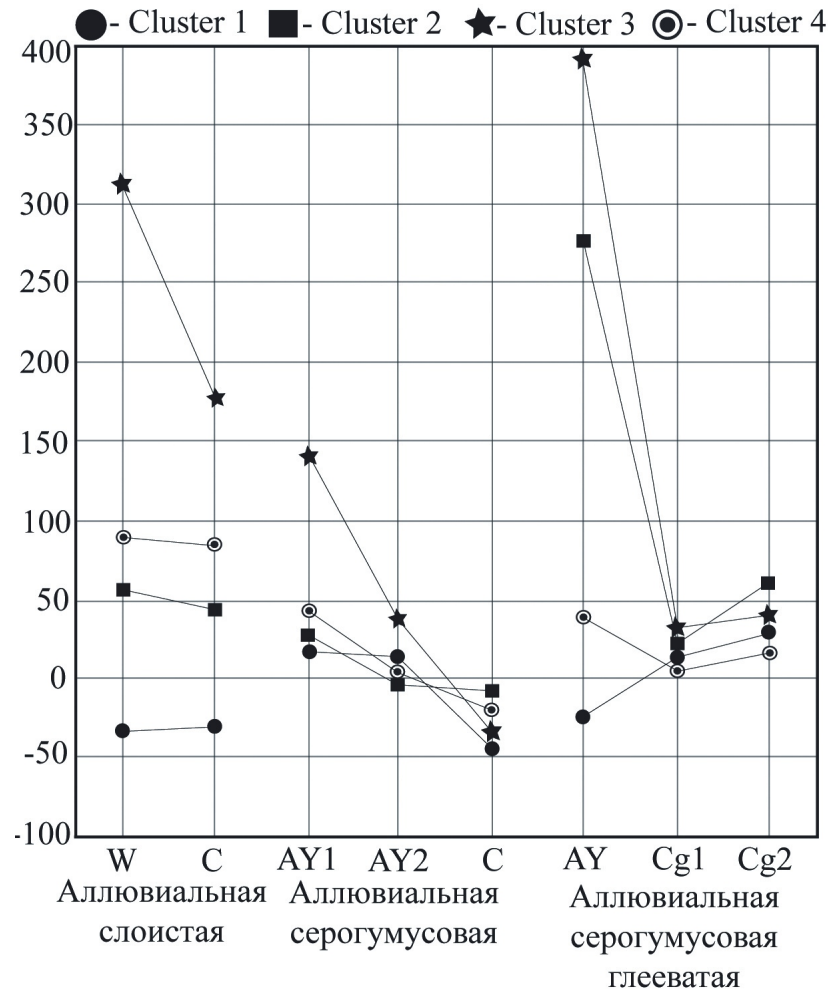

Puc. 4. Изменение содержания подвижной формы микроэлементов после паводка по почвам и горизонтам, \%

K1: $\mathrm{Li}, \mathrm{Cr}, \mathrm{Co}, \mathrm{Rb}, \mathrm{Sr}, \mathrm{Mo}, \mathrm{Cd}, \mathrm{Cs}, \mathrm{Ba}, \mathrm{W}, \mathrm{Tl}$; K2: $\mathrm{Be}, \mathrm{Cu}, \mathrm{Hf}, \mathrm{U}$; K3: Sc, Ni, Th; K4: V, Zn, Ga, As, Y, Zr, Pb

при смещении реакции среды в нейтральную сторонуподвижность этихэлементов снижается.

У элементов кластера 4 высокие R с органическим веществом, оксидами фосфора, марганца и реакцией среды (рис. 3). Данный кластер можно охарактеризовать как органо-минеральный с накоплением элементов в среде близкой к нейтральной. Оксиды фосфора и марганца могут сорбировать микроэлементы [20, 23]. Но, вероятней, данные связи носят вторичный характер и обусловлены накоплением фосфора и марганца органическим веществом.

У элементов 1 кластера достоверныеRс оксидами магния, органическим веществом, физической глиной и емкостью катионного обмена (рис. 3). Этот кластер также можно охарактеризовать как органо-минеральный, но вклад органического вещества в нем проявляется слабее, чем в 1 кластере. Влияние реакции среды на содержание элементов незначительно. 


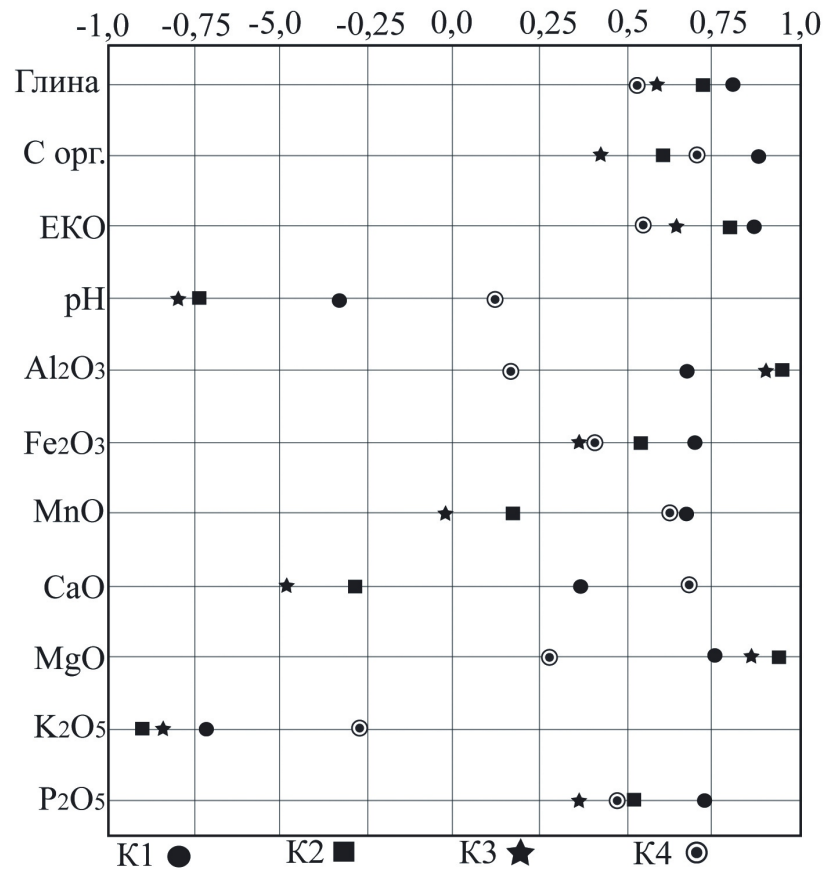

Puc. 5. График средних по кластерам из коэффициентов корреляции содержания подвижных форм микроэлементов, валовых форм макроэлементов и свойств аллювиальных почв после паводка:

K1:Li, Ni, Sr, Mo, Ba, Pb;

К2: $\mathrm{Be}, \mathrm{Cr}, \mathrm{Co}, \mathrm{Rb}, \mathrm{Zr}$, Hf, U;

K3: $\mathrm{Sc}, \mathrm{Cu}, \mathrm{Ga}, \mathrm{Y}, \mathrm{Cs}, \mathrm{Tl}, \mathrm{Th}$; K4: V, Zn, As, Cd, W

Таким образом, до паводка, выделяется две большие группы элементов. Элементы К2 и К3, чья аккумуляция в большей мере обусловлена глинистыми минералами, и подвижность которых снижается при понижении кислотности. И элементы К1 и К4, которые преимущественно накапливаются органическим веществом, а подвижность их снижается при повышении кислотности.

Подвижные фракции микроэлементов очень динамичны и могут меняться за короткий промежуток времени [5]. Поэтому рассматривать на них непосредственное влияние паводка не представляется возможным. Но они реагируют на изменение макроэлементного состава и свойств почв. После паводка содержание элементов К2, К3 и К4 преимущественно увеличилось. Максимальное накопление приходится на верхние горизонты (рис. 4). Содержание элементов К1 преимущественно снизилось.

Причины снижения содержания $\mathrm{Co}, \mathrm{Cr}$ и $\mathrm{Cs}$ неизвестны, так как они по результатам корреляционного анализа аккумулируются на глинистых минералах, а содержание всех остальных элементов, связанных с глинистыми минералами, после паводка увеличилось. Снижение содержания $\mathrm{Li}$, $\mathrm{Rb}, \mathrm{Sr}, \mathrm{Mo}, \mathrm{Cd}, \mathrm{Ba}, \mathrm{W}, \mathrm{Tl}$ может быть обусловлено двумя причинами. Во-первых, после паводка содержание органического вещества снизилось [5], а эти элементы входят в кластеры, у которых высокие R с органическим веществом. Во-вторых, с повышением кислотности почв, обусловленной развитием восстановительных процессов, всегда развивающихся при затоплении почв [21], и вымыванием кальция. Это подтверждается литературными данными, согласно которым $\mathrm{pH}$ оказывает сильнейшее воздействие на видообразование и подвижность металлов как в почвах в целом, так и в почвенном растворе $[17,21,22]$. Для выявления снижения содержания ПМЭ определены их $\mathrm{R}$ со свойствами почв и макроэлементным составом после паводка (рис. 5).

После паводка изменились как составы кластеров, так и их отношения со свойствами почв. Разделение элементов по принципу их аккумуляции на органическом веществе и глинистых минералах стало менее явно. Это связано с тем, что у элементов, у которых до паводка были достоверные $\mathrm{R}$ только с оксидом алюминия, после паводка проявились сильные R с органическим веществом. Также у всех элементов наблюдается смещение $\mathrm{R}$ с $\mathrm{pH}$ в отрицательную сторону.

У элементов, аккумулирующихся глинистыми минералами (К2 и К3), помимо R с органическим веществом, усилились положительные R с оксидом магния, физической глиной и ЕКО (рис. 5). У элементов, которые до паводка характеризовались высокими R с органическим веществом, после паводка значительно сместились их $\mathrm{R} \mathrm{c} \mathrm{pH} \mathrm{в} \mathrm{отри-}$ цательную сторону, а с органическим веществом и оксидом кальция не изменились. Следовательно, развитие восстановительных процессов во время затопления почв, привело к усилению кислотности почв, что подтверждается литературными данными [24]. Элементы, связанные с органическим веществом в этих условиях частично перешли в неподвижное состояние, а подвижность элементов, аккумулирующихся на глинистых минералах повысилась. Максимальное увеличение подвижности элементов наблюдается в органических горизонтах, что связано с сущностью восстановительных процессов. Для их развития необходимо органическое вещество [3], поэтому при затоплении почв они более интенсивно протекали именно в верхних горизонтах.

Помимо изменения почвенных свойств, увеличение содержания ПМЭ может быть вызвано уве- 
Содержание подвижных форм микроэлементов в аллювиальных почвах поймы среднего течения р. Амур и влияние на них паводка 2013 года

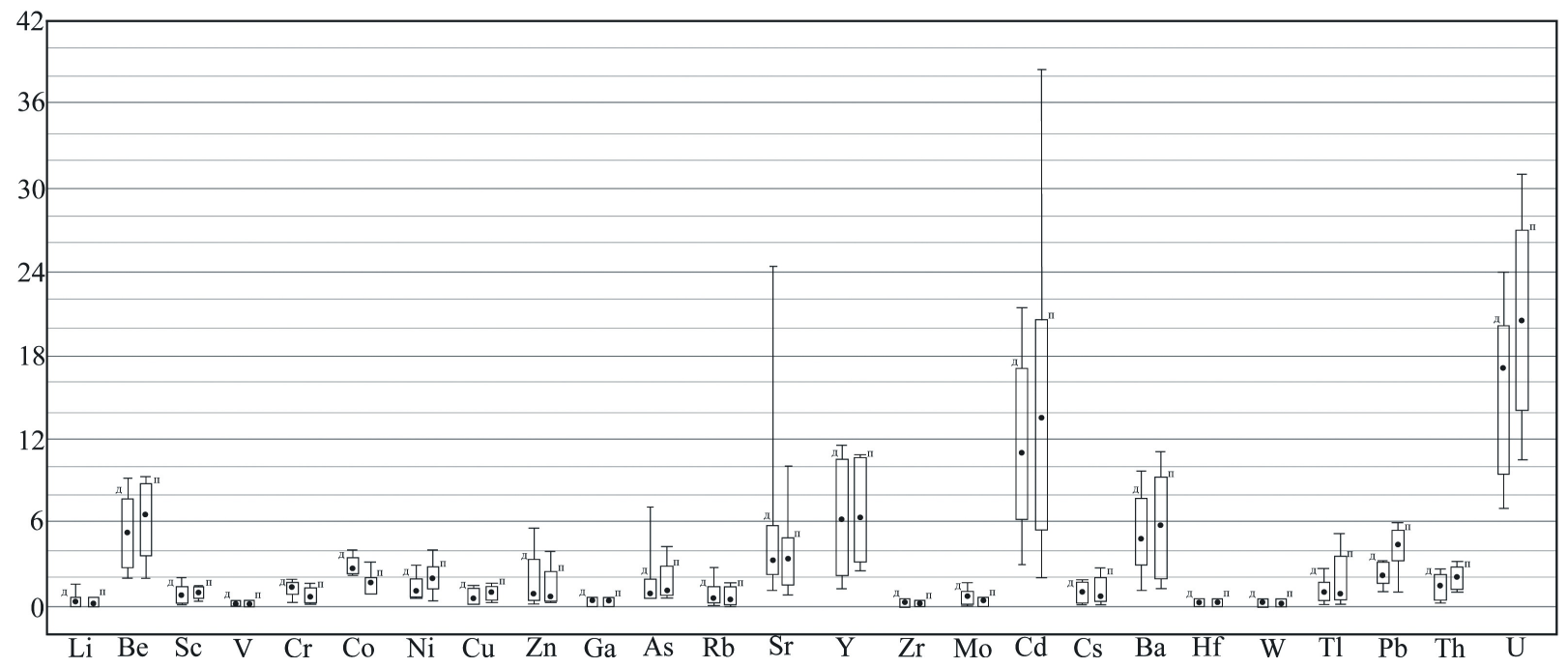

Puc. 6. Средняя по почвам медиана и мин. -мак. содержание подвижных микроэлементов относительно их валового содержания до и после паводка, \% (. - медиана, $\top^{-}$максимум, $\perp_{-}$минимум, $\square-$ область включающая 75 \% данных, д - до паводка, п - после паводка)

личением их валового содержания. Поэтому определено процентное отношение содержания ПМЭ к их валовому содержанию [6] до и после паводка (рис. 6). Если изменение почвенных свойств не повлияло на подвижность микроэлементов, то и их процентное отношение в составе валового содержания после паводка не должно сильно измениться.

Полученные данные показывают, что подвижная форма $\mathrm{Li}, \mathrm{V}, \mathrm{Ga}, \mathrm{Zr}$, Hf и $\mathrm{W}$ в составе валового содержания до и после паводка неизменна (рис. 6). Следовательно, содержание подвижной формы этих элементов в почве зависит преимущественно от валового содержания и слабо реагирует на изменения свойств аллювиальных почв. У $\mathrm{Rb}, \mathrm{Sr}, \mathrm{Co}$, $\mathrm{Cr}$ и Мо наблюдается снижение подвижной формы относительно валового содержания, т.е. повышение кислотности почв и развитие восстановительных процессов обусловили их переход в неподвижное состояние. Содержание подвижной формы $\mathrm{Ba}, \mathrm{Cd}$ и $\mathrm{Tl}$ относительно валового содержания увеличивается после паводка, но их абсолютное содержание снизилось. Это можно объяснить более высоким снижением валового содержания $\mathrm{Ba}, \mathrm{Cd}$ и $\mathrm{Tl}$, чем подвижной формы.

Таким образом, снижение содержания подвижных форм Li и $\mathrm{W}$ обусловлено снижением их валовой формы, $\mathrm{Rb}, \mathrm{Sr}, \mathrm{Co}, \mathrm{Cr}$ и $\mathrm{Mo}-$ изменением $\mathrm{pH}$ и $\mathrm{eH}, \mathrm{a} \mathrm{Ba}, \mathrm{Cd}$ и $\mathrm{Tl}$ - совокупным действием этих факторов. Отдельно следует отметить, что в аллювиальных почвах р. Амур микроэлементы Ве, $\mathrm{Sr}, \mathrm{Y}, \mathrm{Cd}, \mathrm{Ba}, \mathrm{U}$, в сравнении с другими элементами, активно переходят в подвижную форму (рис. 6). Учитывая, что $\mathrm{Be}, \mathrm{Sr}, \mathrm{Cd}, \mathrm{U}$ характеризуются токсичными свойствами, то в случае загрязнения этими элементами поймы реки Амур, они очень быстро начнут распространяться по пищевой цепи.

\section{ЗАКЛЮЧЕНИЕ}

В аллювиальных почвах прирусловой поймы реки Амур наблюдается дефицит необходимых для питания растений подвижных элементов, таких как $\mathrm{Cu}, \mathrm{Mo}, \mathrm{V}, \mathrm{Cr}$. Содержание других жизненно важных элементов, таких как Co, Zn, Ва увеличивается вглубь поймы, но вместе с ними активно накапливаются и токсичные элементы $\mathrm{U}, \mathrm{Cd}, \mathrm{Sr}, \mathrm{Be}$. Pacпределение подвижных микроэлементов преимущественно связано с содержанием глинистых минералов в почвах и органическим веществом. Поводок привел к вымыванию органического вещества, а также к развитию восстановительных процессов и повышению кислотности почв. В результате повысилась мобилизация микроэлементов, аккумуляция которых обусловлена глинистыми минералами. Микроэлементы, адсорбирующиеся на органическом веществе, частично перешли в неподвижную форму или вымылись с органическим веществом. Наиболее интенсивно увеличилось содержание $\mathrm{Sc}, \mathrm{Ni}$, Th, и снизилось - $\mathrm{Li}, \mathrm{Cr}$, $\mathrm{Co}, \mathrm{Rb}, \mathrm{Sr}, \mathrm{Mo}, \mathrm{Cd}, \mathrm{Cs}, \mathrm{Ba}, \mathrm{W}, \mathrm{Tl}$.

\section{СПИСОК ЛИТЕРАТУРЫ}

1. Аринушкина Е. В. Руководство по химическому анализу почв / Е. В. Аринушкина. - Москва : Московский университет, 1970. -487 с. 
2. ГН 2.1.7.2041-06. Предельно допустимые концентрации (ПДК) химических веществ в почве. - URL : https://files.stroyinf.ru/Data2/4293850/4293850511/htm (дата обращения 06.06.2019).

3. Зайдельман Ф. Р. Генезис и экологические основы мелиорации почв и ландшафтов / Ф. Р. Зайдельман. - Москва : Книжный дом Университет, 2009. - 720 с.

4. Ковда В. А. Основы учения о почвах. Общая теория почвообразовательного процесса / В. А. Ковда. Москва : Наука, 1973. - Т. 2. - 468 с.

5. Мартынов А. В. Изменение свойств аллювиальных почв после крупного паводка на примере среднего течения р. Амур / А. В. Мартынов // Современные проблемы науки и образования. - 2016. - № 3. - С. 405.

6. Мартынов А. В. Оценка влияния крупного паводка на содержание микроэлементов в аллювиальных почвах в среднем течении р. Амур / А. В. Мартынов // Бюллетень почвенного института им. В. В. Докучаева. - 2018. - № 91. - С. 110-131.

7. Мартынов А. В. Влияние паводков на содержание редкоземельных элементов в аллювиальных почвах (на примере поймы среднего течения р. Амур) // Вестник Воронежского государственного университета. Сер. География. Геоэкология. - 2018. - № 1. - С. 35-47.

8. Микроэлементы в сельском хозяйстве / С. Ю. Булыгин [и др.]. - Днепропетровск : Січ, 2007. - 100 с.

9. Новицкий М. В. Лабораторно-практические занятия по почвоведению / М. В. Новицкий, И. Н. Донских, Д. В. Чернов. - Санкт-Петербург : Проспект Науки, 2009. - 320 с.

10. Орлов Д. С. Микроэлементы в почвах и живых организмах / Д. С. Орлов // Соровский образовательный журнал. - 1998. - № 1. - С. 61-68.

11. Протасова Н. А. Микроэлементы: Биологическая роль, распределение в почвах, влияние на распространение заболеваний человека и животных / Н. А. Протасова // Соровский образовательный журнал. - 1998. - № 12. - С. 32-37.

12. Скрябина О. А. Минералогический состав почв и почвообразующих пород / О. А. Скрябина. - Пермь : Пермская государственная сельскохозяйственная акамедия, 2011. - 117 с.

13. Фащевский Б. В. Экологическое значение поймы в речных экосистемах / Б. В. Фащевский // Ученые записки Российского государственного гидрометеорологического университета. - 2007. - № 5. - С. 118-129.

14. Классификация и диагностика почв России / Л. Л. Шишов [и др.]. - Смоленск : Ойкумена, 2004. $342 \mathrm{c.}$

15. Шраг В. И. Пойменные почвы, их мелиорация и сельскохозяйственное использование / В. И. Шраг. Москва : Россельхозиздат, 1969. - 273 с.

16. Ягодин Б. А. Агрохимия / Б. А. Ягодин, Ю. П. Жуков, В. И. Кобзаренко. - Москва : Колос, 2002. - 584 с.

17. Effects of redox potential and $\mathrm{pH}$ value on the release of rare earth elements from soil / X. Cao [et al.] // Chemosphere. - 2001. - № 44. - P. 655-661.
18. Florian A. Fast colloidal and dissolved release of trace elements in a carbonatic soil after experimental floodin / A. Florian, B. Moritz, W. Wolfgang // Geoderma. - 2015. - Vol. 259-260. - P. 156-163.

19. Kabata-Pendias A. Trace Elements in Soils and Plants / A. Kabata-Pendias. - Boca Raton : CRC Press, 2011. $-534 \mathrm{p}$.

20. Mihajlovic J. Geochemical fractions of rare earth elements in two floodplain soil profiles at the Wupper River, Germany / J. Mihajlovic, S. Hans-Joachim, J. Rinklebe // Geoderma. - 2014. - № 228-229. - P. 160-172.

21. Ponnamperuma F. N. Effects of Flooding on Soils/ F.N. Ponnamperuma // Flooding and plant growth. London : Academic Press, 1984. - P. 9-46.

22. Schulz-Zunkel C. Trace element release patterns from three floodplain soils under simulated oxidizedreduced cycles / C. Schulz-Zunkel, J. Rinklebe, H.-R. Bork // Ecological Engineering. - 2015. - Vol. 83. - P. 485-495.

23. Schulz-Zunkel F. Trace metal dynamics in floodplain soils of the river Elbe: areview / F. Schulz-Zunkel, F. Krueger // Journal of Environmental Quality. - 2009. Vol. 38. - P. 1349-1362.

24. The influence of $\mathrm{pH}$ and organic matter content in paddy soil on heavy metal availability and their uptake by rice plants / F. Zeng [et al.] // Environmental Pollution. 2011. - Vol. 159, No. 1. - P. 84-91.

25. Trace metal behavior in estuarine and riverine floodplain soils and sediments: a review / G. Du Laing [et al.] // Science of the Total Environment. - 2009. - Vol. 407. - P. 3972-3985.

26. Wei D. Total N, total $P$ and organic matters content in floodplain soils of Xianghai Nature Reserve / D. Wei, Z. Jin-liang // Journal of Geographical Sciences. - 2002. Vol. 12. - № 1. - P. 58-64.

\section{REFERENCES}

1. Arinushkina E. V. Rukovodstvo po khimicheskomu analizu pochv / E. V. Arinushkina. - Moskva : Moskovskiy universitet, 1970. $-487 \mathrm{~s}$.

2. GN 2.1.7.2041-06. Predel'no dopustimye kontsentratsii (PDK) khimicheskikh veshchestv v pochve. - URL : https://files.stroyinf.ru/Data2/4293850/4293850511/htm (data obrashcheniya 06.06.2019).

3. Zaydel'man F. R. Genezis i ekologicheskie osnovy melioratsii pochv i landshaftov / F. R. Zaydel'man. - Moskva : Knizhnyy dom Universitet, 2009. - 720 s.

4. Kovda V. A. Osnovy ucheniya o pochvakh. Obshchaya teoriya pochvoobrazovatel'nogo protsessa / V. A. Kovda. - Moskva : Nauka, 1973. - T. 2. - 468 s.

5. Martynov A. V. Izmenenie svoystv allyuvial'nykh pochv posle krupnogo pavodka na primere srednego techeniya r. Amur / A. V. Martynov // Sovremennye problemy nauki i obrazovaniya. - 2016. - № 3. - S. 405.

6. Martynov A. V. Otsenka vliyaniya krupnogo pavodka na soderzhanie mikroelementov v allyuvial'nykh pochvakh v srednem techenii r. Amur / A. V. Martynov // Byul- 
leten' pochvennogo instituta im. V. V. Dokuchaeva. - 2018. - № 91. - S. 110-131.

7. Martynov A. V. Vliyanie pavodkov na soderzhanie redkozemel'nykh elementov v allyuvial'nykh pochvakh (na primere poymy srednego techeniya r. Amur) // Vestnik Voronezhskogo gosudarstvennogo universiteta. Ser. Geografiya. Geoekologiya. - 2018. - № 1. - S. 35-47.

8. Mikroelementy v sel'skom khozyaystve / S. Yu. Bulygin [i dr.]. - Dnepropetrovsk : Cich, 2007. - 100 s.

9. Novitskiy M. V. Laboratorno-prakticheskie zanyatiya po pochvovedeniyu / M. V. Novitskiy, I. N. Donskikh, D. V. Chernov. - Sankt-Peterburg : Prospekt Nauki, 2009. $-320 \mathrm{~s}$.

10. Orlov D. S. Mikroelementy v pochvakh i zhivykh organizmakh / D. S. Orlov // Sorovskiy obrazovatel'nyy zhurnal. - 1998. - № 1. - C. 61-68.

11. Protasova N. A. Mikroelementy: Biologicheskaya rol', raspredelenie v pochvakh, vliyanie na rasprostranenie zabolevaniy cheloveka i zhivotnykh / N. A. Protasova // Sorovskiy obrazovatel'nyy zhurnal. - 1998. - № 12. - C. 32-37.

12. Skryabina O. A. Mineralogicheskiy sostav pochv i pochvoobrazuyushchikh porod / O. . Skryabina. - Perm' : Permskaya gosudarstvennaya sel'skokhozyaystvennaya akamediya, 2011. - $117 \mathrm{~s}$.

13. Fashchevskiy B. V. Ekologicheskoe znachenie poymy v rechnykh ekosistemakh/B. V. Fashchevskiy // Uchenye zapiski Rossiyskogo gosudarstvennogo gidrometeorologicheskogo universiteta. - 2007. - № 5. - S. 118-129.

14. Klassifikatsiya i diagnostika pochv Rossii / L. L. Shishov [i dr.]. - Smolensk : Oykumena, 2004. - 342 s.

15. Shrag V. I. Poymennye pochvy, ikh melioratsiya i sel'skokhozyaystvennoe ispol'zovanie / V. I. Shrag. - Moskva : Rossel'khozizdat, 1969. - 273 s.

16. Yagodin B. A. Agrokhimiya / B. A. Yagodin, Yu. P. Zhukov, V. I. Kobzarenko. - Moskva : Kolos, 2002. $-584 \mathrm{~s}$.

Мартынов Александр Викторович

кандидат географических наук, научный сотрудник лаборатории геоэкологии Института геологии и природопользования ДВО РАН, г. Благовещенск, т. 8(4162)22-53-35, E-mail: lexx 1981@ list.ru
17. Effects of redox potential and $\mathrm{pH}$ value on the release of rare earth elements from soil / X. Cao [et al.] // Chemosphere. - 2001. - № 44. - P. 655-661.

18. Florian A. Fast colloidal and dissolved release of trace elements in a carbonatic soil after experimental floodin / A. Florian, B. Moritz, W. Wolfgang // Geoderma. 2015. - Vol. 259-260. - P. 156-163.

19. Kabata-Pendias A. Trace Elements in Soils and Plants / A. Kabata-Pendias. - Boca Raton : CRC Press, 2011. $-534 \mathrm{p}$.

20. Mihajlovic J. Geochemical fractions of rare earth elements in two floodplain soil profiles at the Wupper River, Germany / J. Mihajlovic, S. Hans-Joachim, J. Rinklebe // Geoderma. - 2014. - № 228-229. - P. 160-172.

21. Ponnamperuma F. N. Effects of Flooding on Soils/ F.N. Ponnamperuma // Flooding and plant growth. - London : Academic Press, 1984. - P. 9-46.

22. Schulz-Zunkel C. Trace element release patterns from three floodplain soils under simulated oxidized-reduced cycles / C. Schulz-Zunkel, J. Rinklebe, H.-R. Bork // Ecological Engineering. - 2015. - Vol. 83. - P. 485-495.

23. Schulz-Zunkel F. Trace metal dynamics in floodplain soils of the river Elbe: areview / F. Schulz-Zunkel, F. Krueger // Journal of Environmental Quality. - 2009. Vol. 38. - P. 1349-1362.

24. The influence of $\mathrm{pH}$ and organic matter content in paddy soil on heavy metal availability and their uptake by rice plants / F. Zeng [et al.] // Environmental Pollution. 2011. - Vol. 159, No. 1. - P. 84-91.

25 . Trace metal behavior in estuarine and riverine floodplain soils and sediments: a review / G. Du Laing [et al.] // Science of the Total Environment. - 2009. - Vol. 407. P. 3972-3985.

26. Wei D. Total N, total P and organic matters content in floodplain soils of Xianghai Nature Reserve / D. Wei, Z. Jin-liang // Journal of Geographical Sciences. - 2002. Vol. 12. - № 1. - P. 58-64.

Martynov Alexander Viktorovich

Candidate of Geographical Sciences, Scientific researcher of laboratory of geoecology of Institute of geology and nature management of the Far Eastern Branch of the Russian Academy of Sciences, Blagoveshchensk, tel. 8(4162)22-53-35, E-mail: lexx_1981@list.ru 